\title{
Mitogenomic evaluation of the historical biogeography of cichlids toward reliable dating of teleostean divergences Yoichiro Azuma1 ${ }^{1}$ Yoshinori Kumazawa*2,3, Masaki Miya ${ }^{4}$, Kohji Mabuchi ${ }^{1}$ and Mutsumi Nishida ${ }^{1}$
}

\begin{abstract}
Address: ${ }^{1}$ Ocean Research Institute, The University of Tokyo, 1-15-1 Minamidai, Nakano-ku, Tokyo 164-8639, Japan, ${ }^{2}$ Division of Material Science and Biological Science, Graduate School of Science, Nagoya University, Furo-cho, Chikusa-ku, Nagoya 464-8602, Japan, ${ }^{3}$ Department of Information and Biological Sciences, Graduate School of Natural Sciences, Nagoya City University, 1 Yamanohata, Mizuho-cho, Mizuho-ku, Nagoya 467-8501, Japan and ${ }^{4}$ Department of Zoology, Natural History Museum and Institute, Chiba, 955-2 Aoba-cho, Chuo-ku, Chiba 260-8682, Japan

Email: Yoichiro Azuma - azuma@ori.u-tokyo.ac.jp; Yoshinori Kumazawa* - kuma@nsc.nagoya-cu.ac.jp; Masaki Miya - miya@chiba-muse.or.jp; Kohji Mabuchi - mabuchi@ori.u-tokyo.ac.jp; Mutsumi Nishida - mnishida@ori.u-tokyo.ac.jp

* Corresponding author
\end{abstract}

Published: 23 July 2008

BMC Evolutionary Biology 2008, 8:215 doi:10.1/86/147/-2148-8-215

This article is available from: http://www.biomedcentral.com/I47I-2/48/8/215

(c) 2008 Azuma et al; licensee BioMed Central Ltd.

This is an Open Access article distributed under the terms of the Creative Commons Attribution License (http://creativecommons.org/licenses/by/2.0), which permits unrestricted use, distribution, and reproduction in any medium, provided the original work is properly cited.
Received: 18 March 2008

Accepted: 23 July 2008

\begin{abstract}
Background: Recent advances in DNA sequencing and computation offer the opportunity for reliable estimates of divergence times between organisms based on molecular data. Bayesian estimations of divergence times that do not assume the molecular clock use time constraints at multiple nodes, usually based on the fossil records, as major boundary conditions. However, the fossil records of bony fishes may not adequately provide effective time constraints at multiple nodes. We explored an alternative source of time constraints in teleostean phylogeny by evaluating a biogeographic hypothesis concerning freshwater fishes from the family Cichlidae (Perciformes: Labroidei).

Results: We added new mitogenomic sequence data from six cichlid species and conducted phylogenetic analyses using a large mitogenomic data set. We found a reciprocal monophyly of African and Neotropical cichlids and their sister group relationship to some Malagasy taxa (Ptychochrominae sensu Sparks and Smith). All of these taxa clustered with a Malagasy + Indo/Sri Lankan clade (Etroplinae sensu Sparks and Smith). The results of the phylogenetic analyses and divergence time estimations between continental cichlid clades were much more congruent with Gondwanaland origin and Cretaceous vicariant divergences than with Cenozoic transmarine dispersal between major continents.

Conclusion: We propose to add the biogeographic assumption of cichlid divergences by continental fragmentation as effective time constraints in dating teleostean divergence times. We conducted divergence time estimations among teleosts by incorporating these additional time constraints and achieved a considerable reduction in credibility intervals in the estimated divergence times.
\end{abstract}




\section{Background}

Recent technical advances in the molecular estimation of divergence times have provided molecular evolutionists with promising tools to introduce reliable time scales to molecular phylogenetic trees [1]. One of the most significant advances common to these new methods is the departure from the molecular clock assumption, which in many cases does not strictly hold. Another advance is the use of time constraints at multiple nodes, rather than the assignment of a discrete time value to a particular node, for rate calibration. This is useful because of the various uncertainties in divergence time estimations based on fossil evidence. In general, the occurrence of the earliest fossil assignable to a particular branch can define the lower boundary of divergence time for the node at which this branch departed from its sister branch [2]. However, when the corresponding fossil data are inadequate or sparse, the lower time boundary based on such data could considerably postdate the true divergence time, potentially leading to inaccurate or imprecise dating results $[2,3]$.

In general, fossils of bony fishes are not considered well preserved. Of the 425 teleostean families, 181 families do not have a fossil record. Of the remaining 244 that have fossil records, 58 have only otoliths [4]. Thus, lower boundary values of divergence times based on teleostean fossil evidence could underestimate the true values [5-7]. Therefore, alternative methods that may provide effective time constraints in dating teleostean divergences should be explored, e.g., methods based on reasonable biogeographic assumptions. Because freshwater fishes do not disperse easily through saltwater, their evolution may be tightly linked to the geological history of the landmasses on which they evolved $[8,9]$. Thus, evaluating the potential correlation of continental drift and lineage divergences in each of the freshwater fish groups that have multicontinental distributions is important [10].

Cichlids (order Perciformes: family Cichlidae) are freshwater fishes that are mainly distributed in landmasses of Gondwanaland origin (Africa, South and Central America, Madagascar, and Indo/Sri Lanka) [11]. They have experienced an explosive radiation in the Great Lakes of East Africa, and they constitute one of the best-known model organisms for evolutionary biology [12]. Phylogenetic studies based on morphological and molecular evidence have consistently recognized the monophyletic origin of the family, basal divergences of Malagasy and Indo/Sri Lankan taxa, and the sister-group relationship of African and South American clades [13-16]. These patterns of divergence among continental cichlid groups are entirely consistent with the geological history of continental drift, the proposed Gondwanan origin of Cichlidae, and subsequent vicariant divergences $[5,6,13-18]$. How- ever, only a few molecular studies $[7,19]$ have attempted to evaluate this hypothesis by dating cichlid divergences; their different approaches led to opposite conclusions. Genner et al. [7] supported vicariant cichlid divergences during Cretaceous times (vicariant hypothesis), whereas Vences et al. [19] suggested a Cenozoic transmarine dispersal (dispersal hypothesis). The latter conclusion is more consistent with the Eocene occurrence of the oldest cichlid fossils [20].

We used molecular data obtained from complete mitochondrial DNA (mtDNA) sequences to investigate these hypotheses. Among the 54 fish taxa that we sampled, we newly determined the sequence data for six cichlid species. The two alternate hypotheses for cichlids, vicariant and dispersal ones, were evaluated by estimating the divergence times of the taxa using Bayesian analyses that incorporated extensive fossil-based time constraints for various divergences. Despite the relative paucity of fish fossil records, this set of time constraints allowed us to estimate cichlid divergence times with high enough resolution to discriminate between the two alternative hypotheses.

\section{Methods \\ Taxonomic sampling}

Cichlid samples were obtained from local animal dealers in Japan. We combined these new mitogenomic data with 48 previously published sequences from the DDBJ/EMBL/ GenBank nucleotide sequence database. The 10 cichlid taxa that we analyzed (Table 1) cover species from major Gondwana-origin landmasses. In addition, we chose 31 other teleosts, nine basal actinopterygians, and two sarcopterygians. Two sharks were sampled as an outgroup to root the tree. Additional file 1 contains a complete list of the sampled taxa, along with the database accession numbers of their mitogenomic sequences.

\section{DNA extraction, PCR, and sequencing}

Fish samples were excised from live or dead specimens of each species and immediately preserved in $99.5 \%$ ethanol. Total genomic DNA was extracted from muscle, liver, and/or fin clips using a DNeasy tissue kit (Qiagen) or a DNAzol Reagent (Invitrogen), following manufacturer protocols. The mtDNA of each species was amplified using a long-PCR technique with LA-Taq (Takara). Seven fish-versatile primers for long PCR (S-LA-16S-L, L250816S, L12321-Leu, H12293-Leu, H15149-CYB, H106512S, and S-LA-16S-H [21-26]) and the two cichlid-specific primers cichlid-LA-16SH (5'-TTGCGCTACCTTTGCACGGTCAAAATACCG-3') and cichlid-LA-16SL (5'-CGGAGTAATCCAGGTCAGTTTCTATCTATG-3') were used in various combinations to amplify regions covering the entire mtDNA in one or two reactions. The long-PCR 
Table I: Cichlid taxa analyzed for mtDNAs

\begin{tabular}{|c|c|c|c|c|}
\hline Distribution & Name & mtDNA size (bp) & Accession No. & Reference \\
\hline \multirow[t]{4}{*}{ Africa } & Tylochromis polylepis & 16876* & AP009509 & this study \\
\hline & Tropheus duboisi & 16598 & AP0060I5 & [43] \\
\hline & Oreochromis sp. & 16626 & AP009126 & [43] \\
\hline & Neolamprologus brichardi & 16587 & AP0060I4 & {$[43]$} \\
\hline \multirow[t]{2}{*}{ South America } & Astronotus ocellatus & 16569 & AP009127 & [43] \\
\hline & Hypselecara temporalis & 16544 & AP009506 & this study \\
\hline \multirow[t]{3}{*}{ Madagascar } & Paratilapia polleni & 16543 & AP009508 & this study \\
\hline & Paretroplus maculatus & 16486 & AP009504 & this study \\
\hline & Ptychochromoides katria & 16556 & AP009507 & this study \\
\hline Indo/Sri Lanka & Etroplus maculates & 16457 & AP009505 & this study \\
\hline
\end{tabular}

*Nearly complete mtDNA sequences with the control region partially sequenced

products were used as templates for subsequent short PCR.

Over 100 fish-versatile PCR primers [21-27] and 18 taxonspecific primers (Additional file 2) were used in various combinations to amplify contiguous, overlapping segments of the entire mtDNA for each of the six new cichlid species. The long PCR and subsequent short PCRs were performed as described previously [21,28]. The short-PCR reactions were performed using the GeneAmp PCR System 9700 (Applied Biosystems) and Ex Taq DNA polymerase (Takara).

Double-stranded PCR products, treated with ExoSAP-IT (USB) to inactivate remaining primers and dNTPs, were directly used for the cycle sequencing reaction, using dyelabeled terminators (Applied Biosystems) with amplification primers and appropriate internal primers. Labeled fragments were analyzed on Model 3100 and Model 377 DNA sequencers (Applied Biosystems).

\section{Sequence manipulation}

The DNA sequences obtained were edited and analyzed using EditView 1.0.1, AutoAssembler 2.1 (Applied Biosystems) and DNASIS 3.2 (Hitachi Software Engineering Co. Ltd.). Individual gene sequences were identified and aligned with their counterparts in 48 previously published mitogenomes. Amino acid sequences were used to align protein-coding genes, and standard secondary structure models for vertebrate mitochondrial tRNAs [29] were consulted for the alignment of tRNA genes. The $12 \mathrm{~S}$ and $16 \mathrm{~S}$ rRNA sequences were initially aligned using clustalX v. 1.83 [30] with default gap penalties and subsequently adjusted by eye using MacClade 4.08 [31].

The ND6 gene was excluded from the phylogenetic analyses because of its heterogeneous base composition and consistently poor phylogenetic performance [22]. The control region was also excluded because positional homology was not confidently established among such distantly-related species. The third codon positions of protein genes were excluded because of their extremely accelerated rates of change that may cause high levels of homoplasy. After the exclusion of unalignable parts in the loop regions of tRNA genes, as well as the $5^{\prime}$ and/or 3 ' end regions of protein genes, all gene sequences were concatenated to produce 10,034-bp sites (6962, 1402, and 1670 positions for protein-coding, tRNA, and rRNA genes, respectively) for phylogenetic analyses.

\section{Phylogenetic analyses}

Phylogenetic trees were reconstructed using partitioned Bayesian and maximum likelihood analyses. Partitioned Bayesian phylogenetic analyses were performed using MrBayes 3.1.2 [32]. We set four partitions (first codon, second codon, tRNA, and rRNA positions). The general time-reversible model, with some sites assumed to be invariable and variable sites assumed to follow a discrete gamma distribution (GTR $+\mathrm{I}+\Gamma$; [33]), was selected as the best-fit model of nucleotide substitution by MrModeltest 2.2 http://www.abc.se/ nylander/[34]. The Markov chain Monte Carlo (MCMC) process was set so that four chains (three heated and one cold) ran simultaneously. We ran the program for 3,000,000 metropolis-coupled MCMC generations on each analysis, with tree sampling every 100 generations and burn-in after 10,000 trees.

Partitioned maximum likelihood (ML) analyses were performed with RAxML ver. 7.0.3 [35], a program implementing a novel, rapid-hill-climbing algorithm. For each dataset, a rapid bootstrap analysis and search for the bestscoring ML tree were conducted in one single program run, with the GTR $+\mathrm{I}+\Gamma$ nucleotide substitution model. The rapid bootstrap analyses were conducted with 1000 replications, with four threads running in parallel.

Statistical evaluation of alternative phylogenetic hypotheses was done using TREE- PUZZLE 5.2 [36], using the twosided Kishino and Hasegawa (KH) [37] test, the Shimodaira and Hasegawa (SH) [38] test, and Bayes factors 
$[39,40]$. We used the GTR $+\mathrm{I}+\Gamma$ model and its parameters optimized by MrModeltest 2.2.

\section{Divergence time estimation}

For the divergence time estimation, multidistribute program [41] was used by assuming a topological relationship thus obtained, but without assuming the molecular clock (i.e., by allowing heterogeneity in molecular evolutionary rate along branches). Upper and/or lower time constraints at selected nodes were set for the Bayesian MCMC processes to estimate divergence times (including means and 95\% credibility ranges) and relative rates at ingroup nodes. We set the partitioning as described above and first used PAML [42] to optimize the parameters of model F84 and the gamma distribution for eight categories to account for site heterogeneity. Estbranches and multidivtime programs were then used to estimate divergence times. We used 21 fossil-based time constraints assignable to diverse teleostean lineages (Table 2).

\section{Results and discussion}

\section{Mitochondrial genomes of cichlids}

We determined complete or nearly complete mtDNA nucleotide sequences for six new cichlids from Africa, South America, Madagascar, and Indo/Sri Lanka (Table 1 ). The sizes of these genomes ranged from 16,457 to $16,556 \mathrm{bp}$, including approximately $800 \mathrm{bp}$ in the control region. Tylochromis polylepis alone appears to have a somewhat longer control region (approximately $1200 \mathrm{bp}$ ) although the exact sequence of the region was unable to be determined because of the long poly-T sequences within the region. We also analyzed the previously published mitogenomic sequences of four cichlid species (Table 1). Oreochromis mossambicus (accession no. AY597335) was not included because a congeneric taxon (Oreochromis sp.) sequenced by Mabuchi et al. [43] had already been sampled.

All 37 genes encoding two rRNAs, 22 tRNAs, and 13 proteins were identified in these 10 cichlid mitogenomes, basically in the same order and orientation found for most other vertebrates. Transfer RNA genes could be folded into secondary structures typical of vertebrate mitochondrial tRNA [29]. The base composition of cichlid mitogenomes was skewed (data not shown) similarly to those of other vertebrates [44].

\section{Phylogenetic relationships}

Figure 1 shows the phylogenetic relationships inferred from the Bayesian analysis among the 52 bony fishes, estimated with two sharks as an outgroup. The tree topology was identical to that obtained by the partitioned ML analysis (data not shown). These bony fish taxa included two sarcopterygians (coelacanth and lungfish), nine basal actinopterygians (polypterids, acipenseriforms, lepisosteids, and amiid), and 41 teleosts, including 10 cichlids. The phylogenetic relationships obtained for noncichlid taxa (Fig. 1) were largely consistent with those from previous mitogenomic studies $[28,43,45]$, except for

Table 2: Maximum (U) and minimum (L) time constrains (MYA) used for dating at nodes in Fig. 2

\begin{tabular}{|c|c|c|}
\hline Node & Constraint & Reference information \\
\hline A & L4I6 & $\begin{array}{l}\text { Psarolepis fossil (the earliest Sarcopterygii) from Ludlow (Silurian) [2]Lophosteus and Andreolepis fossils (the earliest } \\
\text { Actinopterygii) from Ludlow (Silurian) [64] }\end{array}$ \\
\hline A & U528 & Probable divergence time between chondrichthyans and osteichthyans (528 MYA), based on both fossils and molecules [58] \\
\hline B & L392 & Stem-actinopterans known from the Givetian/Eifelian boundary [57] \\
\hline B & U450 & $\begin{array}{l}\text { Probable divergence time between sarcopterygians and actinopterygians ( } 450 \text { MYA), based on both fossils and molecules } \\
{[6,58]}\end{array}$ \\
\hline C & L345 & Tournasian Cosmoptychius as the earliest stem-group neopterygian [57] \\
\hline C & U392 & Estimated divergence time between polypterids and actinopterans [57] \\
\hline $\mathrm{D}$ & LI30 & Protosephuru (paddlefish) from Hauterivian (Cretaceous) [57] \\
\hline E & L284 & Brachydegma from early Permian [57] \\
\hline $\mathrm{F}$ & LI36 & Stem-hiodontid Yambiania from the Lower Cretaceous [57] \\
\hline G & $\mathrm{LII} 2$ & Osteoglossoid fossil from the Aptian (Cretaceous) [4] \\
\hline $\mathrm{H}$ & LI5I & Stem-elopomorph Elopsomolos from the Kimmeridgian (Jurassic) [57] \\
\hline I & L90 & Albuloid fossil from the Cenomanian (Cretaceous) [4] \\
\hline J & L50 & Anguillid and congrid fossils from the Ypresian (Tertiary) [4] \\
\hline $\mathrm{K}$ & LI46 & Stem-ostariophysan Tischlingerichthys from Tithonian (Jurassic) [57] \\
\hline $\mathrm{L}$ & L57 & Clupeid fossil from the Thanetian (Tertiary) [4] \\
\hline M & L50 & Cyprinid fossil from the Ypresian (Tertiary) [4] \\
\hline$N$ & L74 & Esociform fossil from the Campanian (Cretaceous) [4] \\
\hline $\mathrm{O}$ & L94 & Polymixiid fossil from the Cenomanian (Cretaceous) [4] \\
\hline$P$ & L50 & Pleuronectiform fossil from the Ypresian (Tertiary) [4] \\
\hline Q & L98 & Tetraodontiform fossil from the Cenomanian (Cretaceous) [2] \\
\hline $\mathrm{R}$ & $\mathrm{L} 32$ & Estimated divergence time between Takifugu and Tetraodon [2] \\
\hline
\end{tabular}


a difference in the sister group of holosteans (lepisosteids and amiid).

Although Inoue et al. [28] suggested that the "Ancient Fish Clade" unites acipenserids, lepisosteids, and amiid, our phylogenetic analysis supports the neopterygian clade (lepisosteids + amiid + teleosts), in agreement with an analysis of nuclear DNA sequences [46] and morphological characters [47]. Relationships between the basal actinopterygians and teleosts were not stable against changes in taxonomic representations and the genes used and varied between the two hypotheses (data not shown). We tentatively assumed the neopterygian relationship for subsequent analyses because this was consistent in both morphological and molecular (based on mitochondrial and nuclear sequences) analyses. However, we also conducted analyses to evaluate how our major conclusions in dating depend on the two alternative phylogenetic relationships (Table 3).

In terms of the relationships among 20 percomorphs containing 14 labroids (two labrids, two pomacentrids, and 10 cichlids), we reconfirmed the polyphyly of Labroidei [43] whereby labrids (designated Labroidei 1 in Fig. 1) and cichlids + pomacentirids (Labroidei 2) appear in separate lineages of teleosts. The non-monophyly of the labroid taxa was supported by a number of nodes with $100 \%$ posterior probability and $100 \%$ bootstrap values (Fig. 1).

Among the 10 cichlid taxa that we used, four were from Africa, two from South America, three from Madagascar, and one from Indo/Sri Lanka. The tree (Fig. 1) supports the monophyly of Cichlidae and two other continental groups from Africa and South America. Four basal taxa from Madagascar and Indo/Sri Lanka are not mono- phyletic, and two (Paretroplus from Madagascar and Etroplus from Indo/Sri Lanka) corresponding to Etroplinae sensu Sparks and Smith [16] form a sister group to all other cichlids. The other two Malagasy taxa (Paratilapia and Ptychochromoides), corresponding to Ptychochrominae sensu Sparks and Smith [16], form a sister group to the African + Neotropical clade. These results are consistent with previous molecular studies that used a few mitochondrial or nuclear gene sequences $[14-16,48]$, as well as morphological studies [13].

However, these previous studies did not fully evaluate the statistical significance in rejecting alternative hypotheses of cichlid relationships. We conducted $\mathrm{KH}$ and $\mathrm{SH}$ tests, as well as a test using Bayes factor. Based on these tests, alternative hypotheses assuming the monophyly of Malagasy + Indo/Sri Lankan cichlids (constraint 1), Old World cichlids (constraint 2), and African + Indo/Sri Lankan cichlids (constraint 3 ) are all very unlikely (Table 4 ). These results provide statistical support for the paraphyletic assemblage of the Malagasy + Indo/Sri Lankan taxa to the African + Neotropical clade.

If Cichlidae originated in Cenozoic Africa and migrated into South America, Madagascar, and India via saltwater dispersal $[19,49]$, Malagasy/Indo Sri Lankan and/or Neotropical taxa would probably be nested in the African clade, and alternative relationships (e.g., those corresponding to constraints 2 and 3) would likely appear. However, these relationships were not found, thus supporting the vicariant divergence scenario $[13,14,18]$, at least from a topological standpoint.

\section{Timing of cichlid divergences}

We conducted divergence time estimation among 54 bony fishes, including 10 cichlids (Fig. 2). Twenty-one

Table 3: Comparison of divergence time estimates between different time constraints and studies

\begin{tabular}{|c|c|c|c|c|c|}
\hline Divergence & This study' & This study ${ }^{2}$ & This study ${ }^{3}$ & Yamanoue et al. [55] & Inoue et al. [54] \\
\hline Cichlidae vs. Pomacentridae & $127(107-149)$ & $144(134-154)$ & $137(115-160)$ & - & - \\
\hline Takifugu vs. Tetraodon & $70(55-86)$ & $78(65-93)$ & $76(60-94)$ & $73(57-94)$ & - \\
\hline Tetraodontidae vs. Gasterosteus & $154(|3|-\mid 77)$ & $170(156-185)$ & $161(137-185)$ & $192(153-235)$ & - \\
\hline Cichlidae vs. Oryzias & $136(115-159)$ & $152(14 \mid-165)$ & $148(125-171)$ & - & - \\
\hline Cichlidae/Oryzias vs. Tetraodontidae & $159(136-183)$ & $176(163-191)$ & $166(142-191)$ & $184(154-221)$ & - \\
\hline Percomorpha vs. Beryciformes & $182(157-206)$ & $198(183-215)$ & $188(162-214)$ & $206(174-245)$ & - \\
\hline Acanthopterygii vs. Gadiformes & $191(166-216)$ & $207(190-224)$ & $202(176-229)$ & $223(191-264)$ & - \\
\hline Acanthomorpha vs. Protacanthopterygii & $249(223-274)$ & $262(243-28 I)$ & $270(243-294)$ & $280(240-326)$ & $232(197-267)$ \\
\hline Cyprinus vs. Danio & $139(111-169)$ & $147(120-174)$ & $135(107-164)$ & $167(131-208)$ & - \\
\hline Euteleostei vs. Otocephala & $276(250-301)$ & $288(268-307)$ & $291(264-314)$ & $315(270-363)$ & $278(24|-3| 4)$ \\
\hline Teleostei vs. Amiiformes & $360(339-376)$ & $365(348-378)$ & $381(363-392)$ & $390(340-442)$ & $376(337-413)$ \\
\hline Sarcopterygii vs. Actinopterygii & $428(417-448)$ & $429(417-449)$ & $428(417-449)$ & $470(415-524)$ & $45 I(413-495)$ \\
\hline
\end{tabular}

The means and $95 \%$ credibility ranges (in parentheses) are shown for estimated divergence times.

I Without biogeography-based time constraints on cichlid divergences (see Fig. 2).

2 With biogeography-based time constraints on cichlid divergences (see Fig. 4).

${ }^{3}$ Without biogeography-based time constraints on cichlid divergences, but assuming the Ancient Fish Clade (see text). 


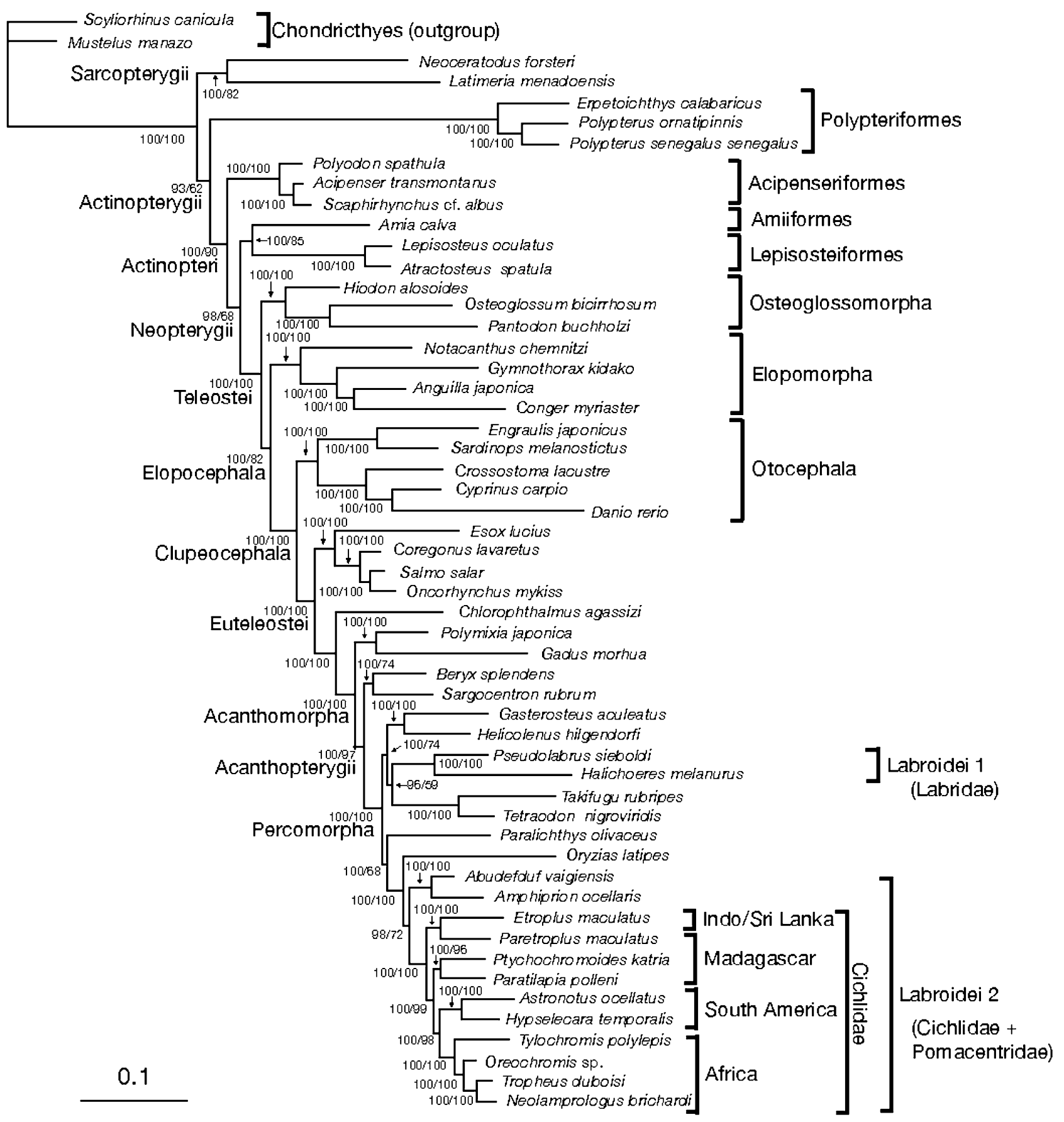

Figure I

A Bayesian tree based on mitogenomic DNA sequences. This is a $50 \%$ majority rule consensus tree among 10,000 pooled trees from two independent Bayesian MCMC runs. The data set comprises aligned gap-free nucleotide sequences of 10,034-bp length from 54 taxa, which included 4,887 variable sites and 3,936 parsimony-informative sites. Partitioned Bayesian analyses were conducted using the GTR $+I+\Gamma$ model and with all model parameters variable and unlinked across partitions. The numerals at internal nodes or branches indicate Bayesian posterior probabilities (left) and maximum likelihood bootstrap probability values (right) from 1000 replicates, respectively (shown as percentage for values above $50 \%$ ). 
Table 4: Test of alternative phylogenetic hypotheses for continental cichlid groups

\begin{tabular}{llll}
\hline Topological constraint & pKH & pSH & 2 In Bayes factor \\
\hline Best as in Fig. I & 1.000 & 1.000 \\
Constraint I: monophyly of Madagascar and Indo/Sri Lanka (Tree I) & $0.006^{* *}$ & $0.043^{*}$ & $65.4^{*}$ \\
Constraint 2: monophyly of Africa, Madagascar and Indo/Sri Lanka (Tree 2) & $0.00 I^{* *}$ & $0.002^{* *}$ & $125.1^{*}$ \\
Constraint 3: monophyly of Africa and Indo/Sri Lanka (Tree 3) & $0.000^{* *}$ & $0.000^{* *}$ & $297.2^{*}$ \\
\hline
\end{tabular}

Probabilities for constrained trees were assessed using the Kishino-Hasegawa (pKH) and Shimodaira-Hasegawa (pSH) tests and the Bayes factor. Single asterisks indicate significant rejection $(p<0.05)$ and double asterisks indicate highly significant rejection $(p<0.01)$ of the corresponding hypothesis. We used the traditional criterion of 2 In Bayes factor over 10 (with an asterisk), indicating very strong evidence against an alternative hypothesis [39]. Constrained trees are the following: Tree I: ((((Oreochromis sp., (Tropheus duboisi, Neolamprologus brichardi)), Tylochromis polylepis),(Astronotus ocellatus, Hypselecara temporalis)),((Etroplus maculatus, Paretroplus maculatus),(Ptychochromoides katria, Paratilapia polleni))); Tree 2: ((((Oreochromis sp.,(Tropheus duboisi, Neolamprologus brichardi)), Tylochromis polylepis),((Etroplus maculatus, Paretroplus maculatus),(Ptychochromoides katria, Paratilapia polleni))),(Astronotus ocellatus, Hypselecara temporalis)); and Tree 3: (((((Oreochromis sp.,(Tropheus duboisi, Neolamprologus brichardi)), Tylochromis polylepis), Etroplus maculatus),((Astronotus ocellatus, Hypselecara temporalis),(Ptychochromoides katria, Paratilapia polleni))), Paretroplus maculatus).

time constraints based on extensive fossil evidence for bony fishes (Table 2) were used. Following the advice of Benton and Donoghue [2] to set fossil-based time constraints as hard lower boundaries and soft upper boundaries, we chose older values for upper boundaries. We estimated the divergence between African + Neotropical cichlids and Malagasy + Indo/Sri Lankan (ptychochrominae) cichlids to be approximately 96 MYA (78-115 MYA at $95 \%$ credibility). The divergences of African vs. Neotropical cichlids and Malagasy vs. Indo/Sri Lankan cichlids within the Etroplinae were estimated to be approximately 89 MYA (72-108 MYA) and 87 MYA (69106 MYA), respectively.

We then compared the estimated divergence times among cichlids and the probable times of continental fragmentation based on geological evidence. The divergence time between Malagasy and Indo/Sri Lankan taxa within Etroplinae ( 87 MYA: 69-106 MYA) is very close to the time of separation between Madagascar and India (85-95 MYA) $[50,51]$. The divergence time estimated between African and Neotropical clades ( 89 MYA: 72-108 MYA) is also close to the time of separation between African and South American landmasses ( 100 MYA) [50,51]. The divergence time between African + Neotropical cichlids and Malagasy ptychochrominae cichlids ( 96 MYA: 78-115 MYA) appears to be somewhat more recent than the time generally accepted for the complete separation of the Indo-Madagascar landmass from Gondwanaland (120130 MYA) [50,51]. However, some studies [52] have postulated an extended connection between India and Antarctica by approximately 112 MYA, which is within the $95 \%$ credibility range for the African/Neotropical vs. ptychochrominae cichlid divergence. Taken together, these results are consistent with the vicariant divergence of continental cichlid groups during Cretaceous times and argue against their Cenozoic dispersal.
Vences et al. [19] calibrated a molecular clock for cichlids that assumed that the divergence time of the most basal endemic lineages in East African Rift lakes (e.g., Tanganyika) corresponds to the geological estimate of the age of the lakes. These estimated divergence times between continental cichlid clades were all in the Cenozoic (rather than the Mesozoic, as we demonstrate in Fig. 2) and supported the hypothesis of long-distance Cenozoic transmarine dispersal of cichlids. This view of the Cenozoic (or latest Cretaceous) origin and transmarine dispersal of cichlids has also been supported by some biogeographers [49] because it is consistent with cichlid fossil records, which first occur in South America and Africa in the Eocene $[20,53]$. However, the clock-based dating procedures of Vences et al. [19] present some problems. The strict molecular clock may not hold for all cichlid lineages [15], and the premise that the oldest endemic cichlid divergence is synchronized with the formation of the lakes may not be valid. Some lineages that had diverged outside the lake may have immigrated in parallel [7]. In addition, there is no definitive, geologically based time estimate for the formation of the lakes.

More recently, Genner et al. [7] used two mitochondrial (cytochrome $b$ and 16S rRNA) and one nuclear (TMO4C4) gene fragments to estimate the divergence times among cichlids. When the cichlid divergence by Gondwanan vicariance was assumed, the resultant divergence times were more consistent with those estimated with time constraints from previous paleontological and molecular studies [2,54-57] than when the Cenozoic cichlid divergence was assumed based on fossil records.

Although we concur on the Gondwanan origin and vicariant divergence of cichlids, Genner et al. [7] evaluated this biogeographic hypothesis somewhat indirectly, in that the fitness of estimated times of cichlid divergences to those obtained with time constraints from previous studies was qualitatively compared between alternative 


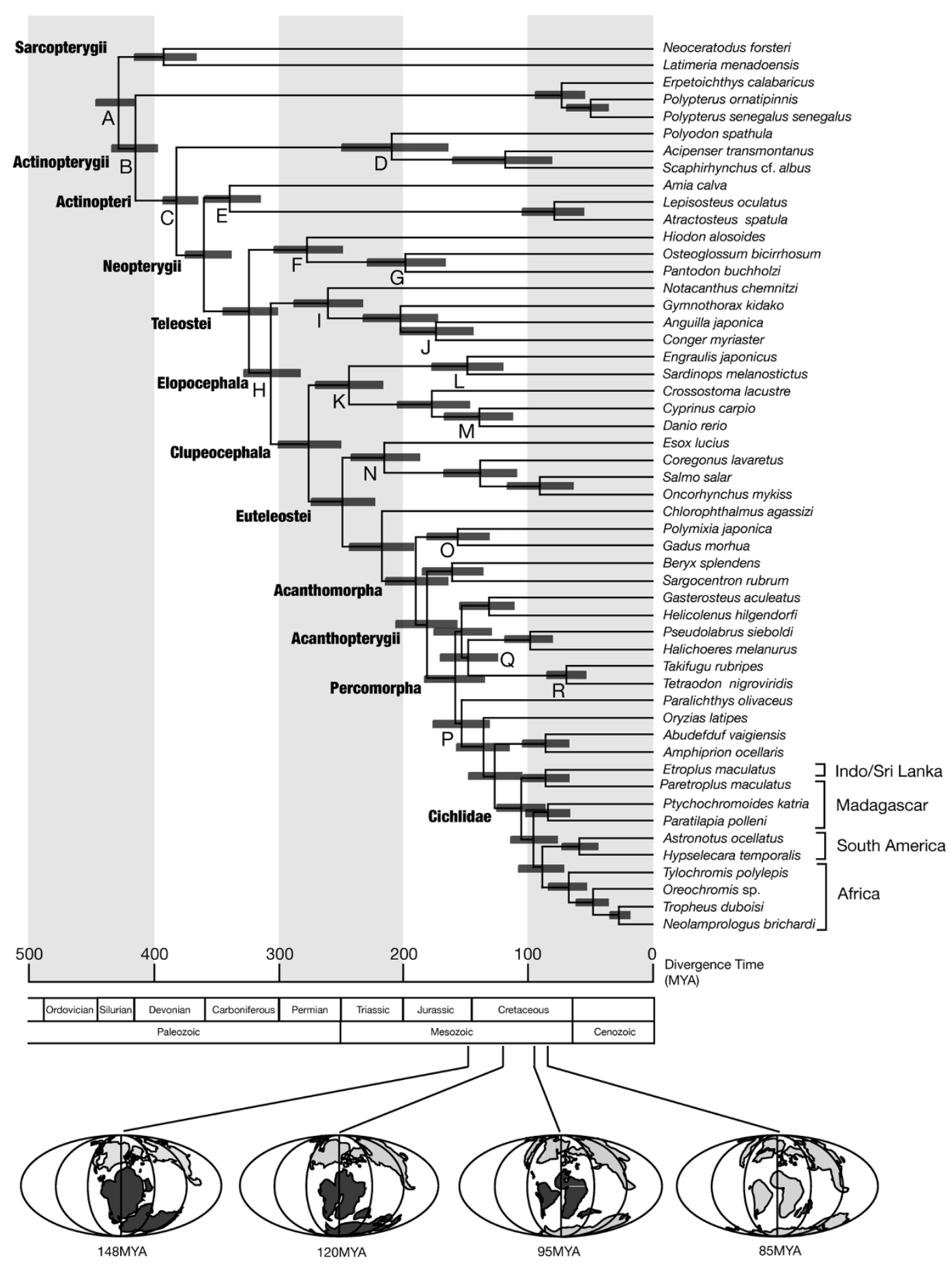

\section{Figure 2}

Divergence times estimated from the partitioned Bayesian analysis. A posterior distribution of divergence times with $95 \%$ credibility intervals (shaded rectangles) was obtained using mitogenomic DNA sequences (I0,034 sites). Two sharks (Scyliorhinus canicula and Mustelus manazo) were used as an outgroup (not shown). The multidistribute program [4I] was used to estimate divergence times assuming the tree topology shown in Fig. I. Letters indicate nodes at which maximum and/or minimum time constraints were set (see Table 2 for details of the individual constraints). Paleogeographical maps at I48 MYA, I 20 MYA, 95 MYA, and 85 MYA [50] are shown. Dark-gray areas on the maps represent those being fragmented within Gondwanaland at those times. 
assumptions on cichlid biogeography. We evaluated cichlid divergence times more directly by using longer mitogenomic sequence data and dozens of non-cichlid taxa, allowing us to set many time constraints purely from the paleontological data and providing additional evidence for an ancient cichlid divergence on Gondwanaland, despite the general paucity of the Mesozoic and Cenozoic paleontological record on bony fishes.

\section{Gondwana fragmentation as time constraints}

In Figure 3, minimum time constraints based on fossil records (see Table 2) are plotted against molecular time estimates of the corresponding divergences (values taken from Fig. 2). In this figure, minimum age estimates of Gondwanan fragmentations are also plotted against the corresponding molecular time estimates of continental cichlid groups. It should be noted here that the latter data points reflecting Gondwanan fragmentation history (closed triangles) are plotted well on the line of 1:1 relationship whereas most of the data points reflecting fossil records (closed circles) are considerably below the line of the 1:1 relationship. This pattern suggests that Gondwana fragmentation history that is congruent with the cichlid phylogeny can be effective time constraints better than most of the Mesozoic and Cenozoic fossil records used here.

Among the fossil data points, four data points in the Paleozoic show a fairly good 1:1 relationship, whereas other points mostly in the Mesozoic are considerably below the line of 1:1 relationship. This might mean that the Mesozoic fossils do not really represent the oldest fossil for the corresponding lineages whereas this is not the case for older Paleozoic lineages. This situation is somewhat reminiscent of the apparent relative paucity of Mesozoic fossil evidence of tetrapods (mammals and birds) [58].

Several papers have noticed that molecular time estimations are consistently older than paleontological ones $[2,3,5-7,59]$. Benton and Ayala [60] have pointed out four pervasive biases that make molecular dates too old: i) too old calibration dates based on previous molecular studies; ii) undetected fast-evolving genes; iii) ancestral polymorphism that is maintained through long evolutionary period; and iv) asymmetric distributions of estimated times, with a constrained younger end but an unconstrained older end (this is caused because rates of evolution are constrained to be nonnegative, but the rates are unbounded above zero).

The first factor is not the case for the present study, because we did not use the calibration dates based on previous molecular studies, but used only those based on fossil records. The third factor would be the case when the used genomic regions are under the long-term balancing

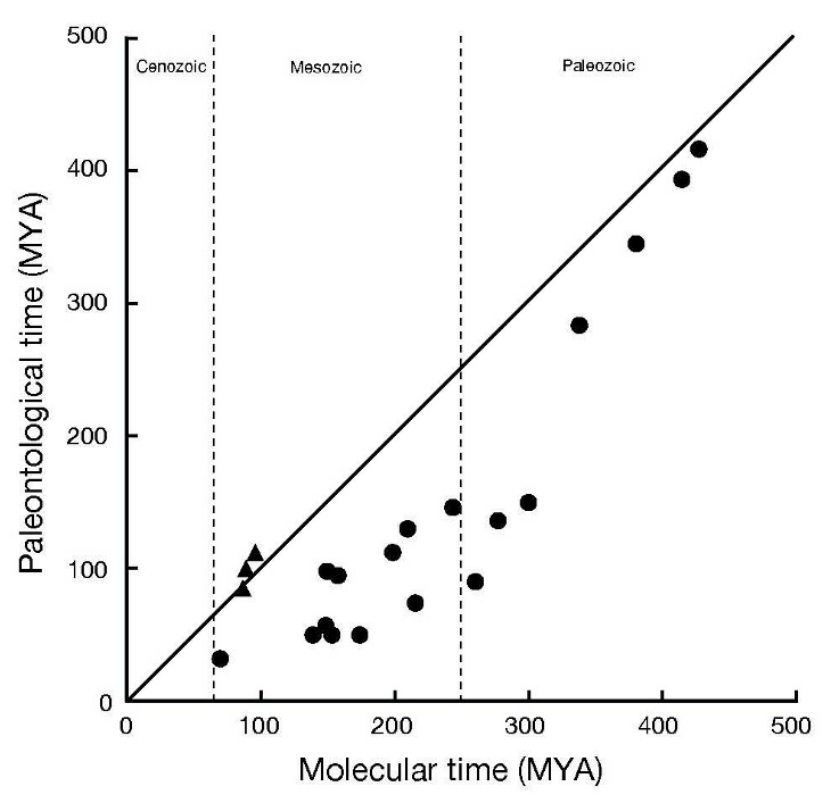

\section{Figure 3}

Comparison of paleontological and molecular estimates of divergence times. Minimum estimates of divergence times deducible from fossil records (see Table 2) were plotted as closed circles against molecularly estimated divergence times (mean values for the divergence times shown in Fig. 2). Closed triangles show plots of the timing of continental breakups against the molecular time estimates of cichlid divergences between the corresponding continents (data taken from Fig. 2). The timings used for complete continental breakups are II 2 MYA for (Africa + South America) vs.

(Madagascar + Indo/Sri Lanka), 100 MYA for Africa vs. South America, and 85 MYA for Madagascar vs. Indo/Sri Lanka [5052]. The solid line indicates a I:I relationship between paleontological and molecular time estimates.

selection, but no mitochondrial gene has been reported to be under such selection. Regarding the second and fourth factors, we believe that they are also not the case for this study, because we used mitogenomic sequence data excluding peculiarly rapid evolving region (e.g., the control region), and because each mitochondrial gene used here was tested to perform well for dating vertebrate (tetrapod) divergences [61]. According to Benton and Ayala [60], for reliable dating "careful choice of genes may be a more appropriate strategy (than the larger data strategy), with a focus on long and fast-evolving (yet alignable) sequences." Our present study based on nearly whole mitogenomic sequence data fairly accommodates such condition.

\section{Improved dating of teleostean divergences}

We then conducted the divergence time estimation using the Gondwanan vicariance assumption regarding cichlids 


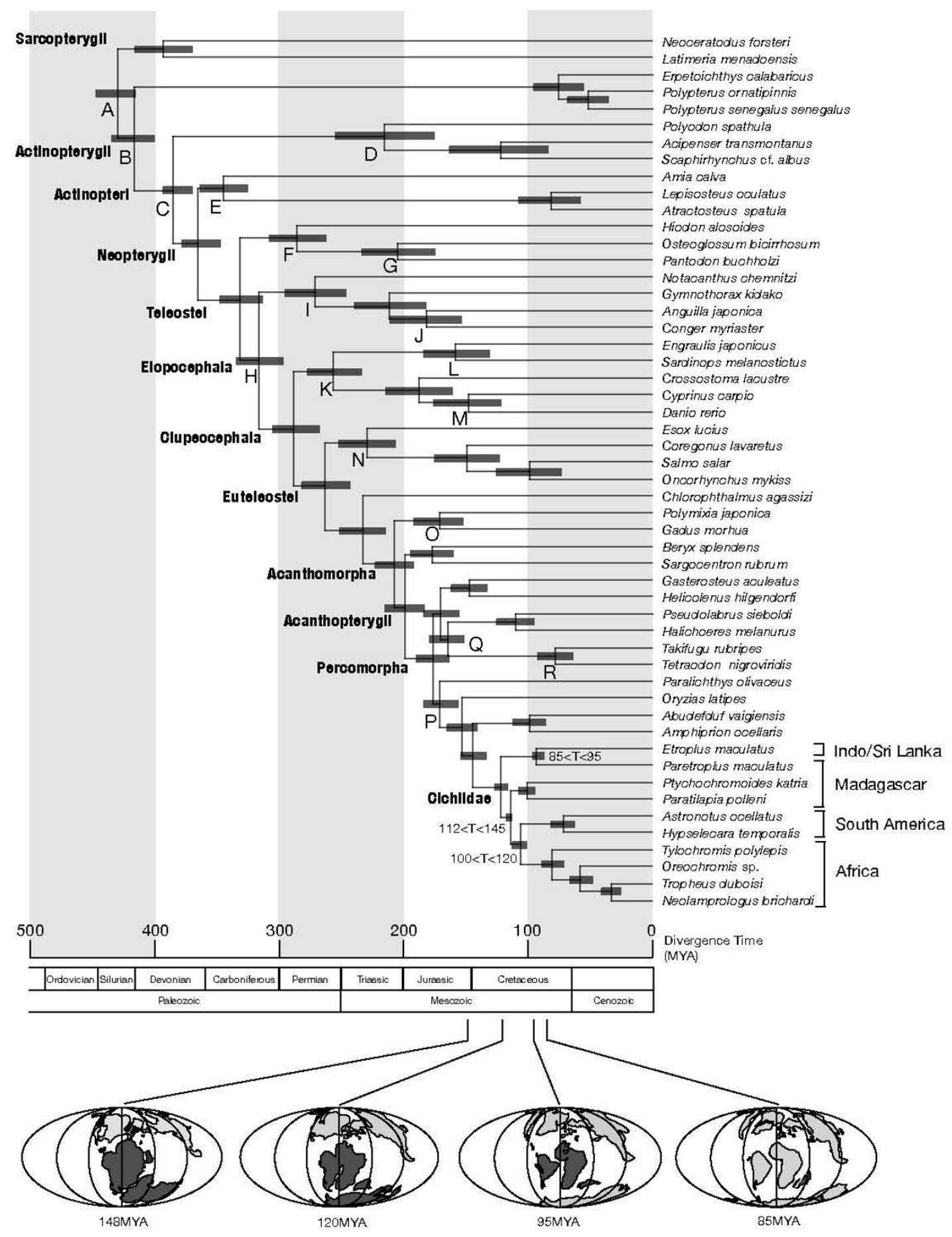

Figure 4

Divergence times estimated from the partitioned Bayesian analysis using both paleontological time constraints (Table 2) and biogeographical assumptions for the divergences of continental cichlid groups. The added time constraints on cichlid divergences are as follows: II 2 MYA (lower) and I45 MYA (upper) for (Africa + South America) vs. (Madagascar + Indo/Sri Lanka); 100 MYA (lower) and I 20 MYA (upper) for Africa vs. South America; and 85 MYA (lower) and 95 MYA (upper) for Madagascar vs. Indo/Sri Lanka [50-52]. See Fig. 2 legend for other details. 
as additional time constraints (Fig. 4). Compared to the results shown in Figure 2 (without the additional time constraints), the means of estimated divergence times at various nodes are similar or somewhat larger (= 18 million years; see Table 3). However, the 95\% credibility ranges of the estimated times overlap well between the two results, and the differences in mean values are not large, compared to potential error ranges in other elements, such as stochastic errors in molecular evolution and errors in dating fossils.

The addition of the cichlid constraints appears to shorten the $95 \%$ credibility intervals of the time estimates, especially for divergences occurring within Acanthomorpha 100-200 MYA. For example, our Figure 2 and Yamanoue et al. [55] estimated the divergence time of torafugu (Tetraodontiformes) and medaka (Beloniformes) to be approximately 159 (136-183) MYA and 184 (154-221) MYA, respectively. The cichlid constraints considerably narrowed the 95\% credibility interval to 176 (163-191) MYA (Table 3), and also increased the precision of time estimates for other nodes. The use of ample molecular data from mitogenomic sequences also helped to narrow the credibility interval. For example, Kumazawa et al. [5] used two mitochondrial genes (NADH dehydrogenase subunit 2 and cytochrome $b$ ) and estimated the divergence between torafugu and zebrafish at $284 \pm 28$ (mean \pm standard deviation) MYA, whereas our whole mitogenomic data set showed the divergence at 288 (268-307) MYA (Table 3).

\section{Conclusion}

We estimated the divergence times of major cichlid lineages as part of the longer evolutionary history of teleostean fishes. Our results and those of a recent molecular study based on both mitochondrial and nuclear data sets [7] support a vicariant history of cichlid divergences, while other researchers [19] have argued for the dispersal hypothesis. We presented additional strong evidence for the vicariant hypothesis and propose that the vicariant assumption can be used to generate time constraints to date other teleostean divergences in both deeper (100300 MYA) and shallower (<100 MYA) time ranges.

This could be a significant contribution toward the reliable dating of teleostean divergence times in light of the scarcity of teleostean fossil records in the Mesozoic and later (see above) and the probable deviation of molecular evolutionary rates of fishes from those of tetrapods [5,62], for which molecular evolutionary rates are more reliably studied using ampler fossil records. A further exploration of biogeography-based time constraints for other groups of freshwater fishes that could be reasonably incorporated into the dating study (e.g. rainbowfishes [63]) would be expected to increase the accuracy and precision of teleostean divergence time estimates.

\section{Authors' contributions}

$\mathrm{YK}, \mathrm{MM}$, and $\mathrm{MN}$ designed the study. YA carried out the molecular work and analyzed the data. MM and KM participated in the data analysis. YA and YK drafted the original manuscript. $\mathrm{MM}$ and $\mathrm{KM}$ contributed to the improvement of all versions of the manuscript. The publication fee was provided by YK. All authors read and approved the final manuscript.

\section{Additional material}

\section{Additional File 1}

List of species used, with database accession numbers. Classifications follow Nelson [11].

Click here for file

[http://www.biomedcentral.com/content/supplementary/1471-

2148-8-215-S1.doc]

\section{Additional File 2}

Cichlid-specific primers for PCR and sequencing. $H$ and $L$ indicate the orientation of the primers. The locations of the primers are shown with the names of the targeted genes.

Click here for file

[http://www.biomedcentral.com/content/supplementary/14712148-8-215-S2.doc]

\section{Acknowledgements}

We thank J. G. Inoue and Y. Yamanoue for their helpful suggestions and technical assistance. We also thank J. G. Inoue for critically reading an earlier version of the manuscript and providing useful comments. This study was supported by grants from the Ministry of Education, Culture, Sports, Science, and Technology of Japan (grant No. I5380 I3I, I7207007, 19207007 and 20405012).

\section{References}

I. Yang Z: Computational Molecular Evolution. New York: Oxford University Press; 2006.

2. Benton MJ, Donoghue PC: Paleontological evidence to date the tree of life. Mol Biol Evol 2007, 24:26-53.

3. Hedges SB, Kumar S: Precision of molecular time estimates. Trends Genet 2004, 20:242-247.

4. Benton MJ: The Fossil Record Volume 2. London: Chapman \& Hall; 1993.

5. Kumazawa Y, Yamaguchi M, Nishida M: Mitochondrial molecular clocks and the origin of euteleostean biodiversity: Familial radiation of perciforms may have predated the Cretaceous/ Tertiary boundary. In The biology of biodiversity Edited by: Kato $M$. Tokyo: Springer; 1999:35-52.

6. Kumazawa $Y$, Nishida M: Molecular phylogeny of osteoglossoids: A new model for Gondwanian origin and plate tectonic transportation of the Asian arowana. Mol Biol Evol 2000, I 7:1869-1878.

7. Genner MJ, Seehausen O, Lunt DH, Joyce DA, Shaw PW, Carvalho GR, Turner GF: Age of cichlids: new dates for ancient lake fish radiations. Mol Biol Evol 2007, 24: I 269-I 282.

8. Banarescu P: Zoogeography of fresh waters. Wiesbaden: AULAVerlag; 1990.

9. Lundberg JG: African-South American freshwater fish clades and continental drift: Problems with a paradigm. In Biological 
relationships between Africa and South America Edited by: Goldblatt P. New Haven: Yale University Press; 1993:156-198.

10. Avise JC: Phylogeography: The History and Formation of Species. Cambridge: Harvard University Press; 2000.

II. Nelson JS: Fishes of the world. 4th edition. Hoboken: John Wiley \& Sons; 2006.

12. Kocher TD: Adaptive evolution and explosive speciation: the cichlid fish model. Nat Rev Genet 2004, 5:288-298.

13. Stiassny MLJ: Phylogenetic intrarelationships of the family Cichlidae: an overview. In Cichlid Fishes: behaviour, ecology and evolution Edited by: Keenleyside MHA. London: Chapman \& Hall; |99|:I-35.

14. Zardoya R, Vollmer DM, Craddock C, Streelman JT, Karl S, Meyer A Evolutionary conservation of microsatellite flanking regions and their use in resolving the phylogeny of cichlid fishes (Pisces: Perciformes). Proc R Soc Lond B 1996, 263:I589-I598.

I5. Farias IP, Orti G, Meyer A: Total evidence: molecules, morphology, and the phylogenetics of cichlid fishes. J Exp Zool 2000, 288:76-92.

16. Sparks JS, Smith WL: Phylogeny and biogeography of cichlid fishes (Teleostei: Perciformes: Cichlidae). Cladistics 2004 20:501-5I7.

17. Chakrabarty P: Cichlid biogeography: comment and review. Fish Fish 2004, 5:97-119.

18. Sparks JS, Smith WL: Freshwater fishes, dispersal ability, and nonevidence: "Gondwana Life Rafts" to the rescue. Syst Biol 2005, 54: $158-165$

19. Vences M, Freyhof J, Sonnenberg R, Kosuch J, Veith M: Reconciling fossils and molecules: Cenozoic divergence of cichlid fishes and the biogeography of Madagascar. J Biogeogr 200I, 28:1091-1099.

20. Murray AM: The fossil record and biogeography of the Cichlidae (Actinopterygii : Labroidei). Biol J Linn Soc 200I, 74:5 I 7-532.

21. Miya M, Nishida M: Organization of the mitochondrial genome of a deep-sea fish, Gonostoma gracile (Teleostei : Stomiiformes): first example of transfer RNA gene rearrangements in bony fishes. Mar Biotechnol 1999, I:4 I 6-426.

22. Miya $M$, Nishida $M$ : Use of mitogenomic information in teleostean molecular phylogenetics: a tree-based exploration under the maximum-parsimony optimality criterion. Mol Phylogenet Evol 2000, I 7:437-455.

23. Inoue JG, Miya M, Tsukamoto K, Nishida M: Complete mitochondrial DNA sequence of the Japanese sardine Sardinops melanostictus. Fish Sci 2000, 66:924-932.

24. Inoue JG, Miya M, Tsukamoto K, Nishida M: A mitogenomic perspective on the basal teleostean phylogeny: resolving higherlevel relationships with longer DNA sequences. Mol Phylogenet Evol 200I, 20:275-285.

25. Ishiguro N, Miya M, Nishida M: Complete mitochondrial DNA sequence of ayu, Plecoglossus altivelis. Fish Sci 200I, 67:474-48I

26. Kawaguchi A, Miya M, Nishida M: Complete mitochondrial DNA sequence of Aulopus japonicus (Teleostei : Aulopiformes), a basal Eurypterygii: longer DNA sequences and higher-level relationships. Ichthyol Res 2001, 48:213-223.

27. Inoue JG, Miya M, Aoyama J, Ishikawa S, Tsukamoto K, Nishida M: Complete mitochondrial DNA sequence of the Japanese eel Anguilla japonica. Fish Sci 2001, 67:1 18-125.

28. Inoue JG, Miya M, Tsukamoto K, Nishida M: Basal actinopterygian relationships: a mitogenomic perspective on the phylogeny of the "ancient fish". Mol Phylogenet Evol 2003, 26: I I0-I20.

29. Kumazawa $Y$, Nishida M: Sequence evolution of mitochondrial tRNA genes and deep-branch animal phylogenetics. J Mol Evol 1993, 37:380-398.

30. Thompson JD, Gibson TJ, Plewniak F, Jeanmougin F, Higgins DG: The CLUSTAL_X windows interface: flexible strategies for multiple sequence alignment aided by quality analysis tools. Nucleic Acids Res 1997, 25:4876-4882.

31. Maddison WP, Maddison DR: MacClade 4.0: analysis of phylogeny and character evolution. Sunderland: Sinauer Associates 2000.

32. Huelsenbeck JP, Ronquist F: MRBAYES: Bayesian inference of phylogenetic trees. Bioinformatics 200I, I 7:754-755.

33. Yang ZH: Maximum likelihood phylogenetic estimation from DNA sequences with variable rates over sites: approximate methods. J Mol Evol |994, 39:306-3।4.
34. Nylander JA, Ronquist F, Huelsenbeck JP, Nieves-Aldrey JL: Bayesian phylogenetic analysis of combined data. Syst Biol 2004, 53:47-67.

35. Stamatakis A: RAxML-VI-HPC: maximum likelihood-based phylogenetic analyses with thousands of taxa and mixed models. Bioinformatics 2006, 22:2688-2690.

36. Schmidt HA, Strimmer K, Vingron M, von Haeseler A: TREE-PUZZLE: maximum likelihood phylogenetic analysis using quartets and parallel computing. Bioinformatics 2002, I 8:502-504.

37. Kishino $\mathrm{H}$, Hasegawa $\mathrm{M}$ : Evaluation of the maximum likelihood estimate of the evolutionary tree topologies from DNA sequence data, and the branching order in Hominoidea. J Mol Evol 1989, 29:170-179.

38. Shimodaira H, Hasegawa M: Multiple comparisons of log-likelihoods with applications to phylogenetic inference. Mol Biol Evol 1999, I6:II14-I II6.

39. Kass RE, Raftery AE: BAYES FACTORS. J Am Stat Assoc 1995, 90:773-795.

40. Brandley MC, Schmitz A, Reeder TW: Partitioned Bayesian analyses, partition choice, and the phylogenetic relationships of scincid lizards. Syst Biol 2005, 54:373-390.

4I. Thorne JL, Kishino H, Painter IS: Estimating the rate of evolution of the rate of molecular evolution. Mol Biol Evol 1998, I 5:1647-1657.

42. Yang ZH: PAML: a program package for phylogenetic analysis by maximum likelihood. Comput Appl Biosci 1997, I3:555-556.

43. Mabuchi K, Miya M, Azuma Y, Nishida M: Independent evolution of the specialized pharyngeal jaw apparatus in cichlid and labrid fishes. BMC Evol Biol 2007, 7:10.

44. Asakawa S, Kumazawa Y, Araki T, Himeno H, Miura K, Watanabe K: Strand-specific nucleotide composition bias in echinoderm and vertebrate mitochondrial genomes. I Mol Evol 1991, 32:5 I I-520

45. Miya M, Takeshima $H$, Endo $H$, Ishiguro NB, Inoue JG, Mukai T, Satoh TP, Yamaguchi M, Kawaguchi A, Mabuchi K, Shirai SM, Nishida M: Major patterns of higher teleostean phylogenies: a new perspective based on 100 complete mitochondrial DNA sequences. Mol Phylogenet Evol 2003, 26: I 2 I- I 38.

46. Kikugawa K, Katoh K, Kuraku S, Sakurai H, Ishida O, Iwabe N, Miyata $\mathrm{T}$ : Basal jawed vertebrate phylogeny inferred from multiple nuclear DNA-coded genes. BMC Biol 2004, 2:3.

47. Patterson C: Interrelationships of holosteans. In Interrelationships of fishes Edited by: Greenwood PH, Miles RS, Patterson C. London: Academic Press; 1973:233-305.

48. Streelman JT, Karl SA: Reconstructing labroid evolution with single-copy nuclear DNA. Proc R Soc Lond B 1997, 264: I 0 I I- 1020.

49. Briggs JC: Fishes and birds: Gondwana life rafts reconsidered. Syst Biol 2003, 52:548-553.

50. Smith AG, Smith DG, Funnell BM: Atlas of Mesozoic and Cenozoic coastlines. New York: Cambridge University Press; 1994.

51. Storey BC: The role of mantle plumes in continental breakup: case histories from Gondwanaland. Nature 1995, 377:301-308.

52. Masters JC, de Wit MJ, Asher RJ: Reconciling the origins of Africa, India and Madagascar with vertebrate dispersal scenarios. Folia Primatol 2006, 77:399-4I8.

53. Malabarba MC, Zuleta O, Del Papa C: Proterocara argentina, a new fossil cichlid from the Lumbrera Formation, Eocene of Argentina. J Vertebr Paleontol 2006, 26:267-275.

54. Inoue JG, Miya M, Venkatesh B, Nishida M: The mitochondrial genome of Indonesian coelacanth Latimeria menadoensis (Sarcopterygii : Coelacanthiformes) and divergence time estimation between the two coelacanths. Gene 2005, 349:227-235.

55. Yamanoue Y, Miya M, Inoue JG, Matsuura K, Nishida M: The mitochondrial genome of spotted green pufferfish Tetraodon nigroviridis (Teleostei : Tetraodontiformes) and divergence time estimation among model organisms in fishes. Genes Genet Syst 2006, 8 I:29-39.

56. Steinke D, Salzburger W, Meyer A: Novel relationships among ten fish model species revealed based on a phylogenomic analysis using ESTs. J Mol Evol 2006, 62:772-784.

57. Hurley IA, Mueller RL, Dunn KA, Schmidt EJ, Friedman M, Ho RK, Prince VE, Yang ZH, Thomas MG, Coates MI: A new time-scale for ray-finned fish evolution. Proc $R$ Soc Lond B 2007, 274:489-498.

58. Kumar S, Hedges SB: A molecular timescale for vertebrate evolution. Nature 1998, 392:917-920. 
59. Wray GA, Levinton JS, Shapiro LH: Molecular evidence for deep precambrian divergences among metazoan phyla. Science 1996, 274:568-573.

60. Benton MJ, Ayala FJ: Dating the tree of life. Science 2003, 300:1698-1700.

61. Kumazawa Y, Azuma Y, Nishida M: Tempo of mitochondrial gene evolution: Can mitochondrial DNA be used to date old divergences? Endocytobiosis Cell Res 2004, 15:136-142.

62. Martin AP, Palumbi SR: Body size, metabolic rate, generation time, and the molecular clock. Proc Natl Acad Sci USA 1993, 90:4087-4091.

63. Sparks JS, Smith WL: Phylogeny and biogeography of the Malagasy and Australasian rainbowfishes (Teleostei : Melanotaenioidei): Gondwanan vicariance and evolution in freshwater. Mol Phylogenet Evol 2004, 33:7 I9-734.

64. Botella $\mathrm{H}$, Blom $\mathrm{H}$, Dorka M, Ahlberg PE, Janvier P: Jaws and teeth of the earliest bony fishes. Nature 2007, 448:583-586.

Publish with Bio Med Central and every scientist can read your work free of charge

"BioMed Central will be the most significant development for disseminating the results of biomedical research in our lifetime. "

Sir Paul Nurse, Cancer Research UK

Your research papers will be:

- available free of charge to the entire biomedical community

- peer reviewed and published immediately upon acceptance

- cited in PubMed and archived on PubMed Central

- yours - you keep the copyright

Submit your manuscript here:

http://www.biomedcentral.com/info/publishing_adv.asp
BiolMedcentral 